\title{
Valuating the Value and Risk of International Start-up Ventures
}

\author{
Ido Kallir ${ }^{1} \&$ Tamir Agmon ${ }^{2}$ \\ ${ }^{1}$ The Graduated School of Business, Ono Academic College, Kiryat Ono, Israel \\ ${ }^{2}$ School of Business, Economics and Law, Goteborg University, Gothenburg, Sweden \\ Correspondence: Ido Kallir, Assistant Professor, The Graduated School of Business, Ono Academic College, Kiryat \\ Ono, Israel. E-mail: ikallir@gmail.com
}

Received: February 8, 2015

Accepted: February 28, 2015

Online Published: April 19, 2015

doi:10.5430/ijfr.v6n2p203

URL: http://dx.doi.org/10.5430/ijfr.v6n2p203

\begin{abstract}
Fair value depends on an estimate of the both cash flow and risk, which is not an easy task when valuing startup firms. We present a measurement instrument for the future risk of small and risky firms that follows the major propositions in accounting and finance. It differs from other valuation instruments in looking simultaneously at the assets and liabilities. We test the VBB as a measure for value over time by using a database of VC backed innovative companies that oridary DCF valuation fails to capture their value. We show that the VBB is an effective way to capture the dynamics of the value of high risk firms.
\end{abstract}

Keywords: fair value, valuation, capital structure, simulation, venture capital

\section{Introduction}

The common valuation model in financial economics is based on a perfect and complete market where information is shared by the market participants. There are situations in the market where the common valuation model is inappropriate. One such situation pertains to young small innovative technology firms known as 'start-ups'. Oftentime the investors do not know how to value them, particularly in cases where they are located in what is for most investors foreign markets. In addition, in most cases these start-ups have no financial history and their radical innovative nature makes it hard to evaluate the information that they provide. Moreover, some of the information is proprietary and is regareded as intellectual property not to be disclosed.

The market in which such startups operate can is imperfect, (for example some of the start-ups are protected by patents). As was hown by Fama and Miller (1972) in a world of imperfect market the value of the firm depends on both the assets of the firms and its liabilities. In particular, the capital structure of the firm has an impact on its value. In such cases both the assets and the liabilities of the firm should be valued together. Common valuation models and prctices are based on the perfect market model and they value the assets of the firm only.

In this paper we develop and discuss a valuation instrument that address this issue called Value Based Balance Sheet (VBB). TheVBB is an instrument to value firms where both assets and liabilities affect the value of the firm. The instrument, called the value based balance sheet (VBB), is based on the identity of both the current value of assets and liabilities and the identity of the risk profile of the assets and the liabilities of the firm. The VBB measures in an explicit way the value and the risk of the assets and the liabilities in an imperfect market. In such a world, it is possible and even likely that, given a particular type of assets, there is an optimal set of liabilities (including equity) that together will maximize the value of the firm. For example, if the assets are very risky, we would expect them to be financed by equity only.

The rest of the study is organized as follows: In Section 2, the VBB is defined and discussed using a numerical example. The example demonstrates what data is needed and how the VBB is used to value assets and liabilities. In Section 3, we discuss the VBB in the context of financial economics. We begin with the classic MM valuation model and then we apply the concept of risk classes as it is discussed in Fama and Miller (1972). We develop two related concepts: financial congruence and derived internal and external liabilities. The risk class is given by the nature of the firm, the choice of which securities to issue is a management decision. In Section 4 we test the VBB as a financial management tool on a data set of venture capital backed firms. In Section 5 we estimated the value of the firms in the sample using VBB based on the five-year expected sales and on the intellectual property (IP) values using various simulation techniques. We conclude in Section 6 with a discussion of the VBB as an instrument to 
improve valuation of very high risk firms operating in an imperfect market where knowledge is proprietary.

\section{A Definition and Discussion of VBB}

The VBB is based on looking at the future cashflows and the future payments of the firm and classify them according to their risk. In a traditional balance sheet the identity between assets and liabilities is limited to their current value as both assets and liabilities are certain. The VBB is based on the economic balance sheet where both assets (risk adjusted future cash flows) and liabilities and net worth (risk adjusted future payments) are uncertain. The accounting identity means in this case the the value and the risk profile of the assets are identically equal to the value and the risk profile of the liabilities.

To see how the VBB is measured and interpreted, consider the following example:

\section{Value Based Balance Sheet of Firm i}

\section{4- 2019}

\section{(Millions of \$)}

\begin{tabular}{lrll}
\hline ASSETS & \multicolumn{3}{l}{ LIABILITIES AND NET WORTH } \\
\hline & & Liabilities to Workers & 90 \\
\hline Sales of Product A in Market 1 & 150 & Suppliers & 30 \\
\hline Sales of Product A in Market 2 & 80 & Service providers & 25 \\
\hline & & Bondholders & 20 \\
\hline & Shareholders & 65 \\
\hline Total Assets & Total Liabilities & $\mathbf{2 3 0}$ \\
\hline
\end{tabular}

The assets in the balance sheet above are the present value of the cash flows to be derived from future sales. The planning horizon is five years (2013-2018) plus the computed residual value from that point. We assume that the future cash flows over time are normally distributed with an expected value $E(C F)_{t}$ and a standard deviation $\sigma(C F)_{t}$. The derived liabilities are divided into two parts; wage is fixed and is treated as a riskless bond issued by the firm to the employees. The other derived liabilities (to suppliers, service providers and such like) are contingent on sales and thus are assumed to be normally distributed with a lower expected value and an identical standard deviation. (Note 1) Assume further that the markets estimate the distributions (Note 2) in the same way as the firm. Given the riskless bond that the firm issued to its employees, the capability of the firm to issue another riskless bond given the assumed distribution of the future cash flows is estimated at $\$ 20 \mathrm{MM}$ (in present value terms). Therefore, in the VBB, the discretionary financial liabilities are \$20MM of riskless debt, and \$65MM of equity, (also in present value terms). For simplicity, assume that both riskless bonds and equity are held by the same investors. The measurement of the assets and the liabilities of the firm in the example above are similar in nature to using Level 3 data in terms of IFRS 13. In this case, internal data of the firm are used to form the value of the assets, and that value is reflected in the liabilities. The above is a simplistic example to show how the VBB of a specific firm is measured. In the empirical part of this paper, we estimated the VBB for a specific group of firms and derived a valuation. This valuation is consistent with both IFRS 13 and with the financial economics valuation model.

The VBB is congruent with recent development in accounting. Fair value measurement is a main feature of IFRS accounting. As of January 2013, the process of introducing IFRS 13 Fair Value measurement became mandatory, although it has been adopted earlier in many countries. In May 2011, the International Accounting Standards Board (IASB) published a detailed analysis of the fair value measurement (IFRS, 2011). IFRS 13 goes beyond current market prices and allows for forecasts to be used as inputs for valuation. In this way the VBB that uses internal data of the firm like business plans is congruent with IFRS13.

The VBB is composed as follows:

1). Assets and liabilities in the VBB are calculated as the discounted cash flows of the revenues (assets) and the expenditures (liabilities). Therefore, the VBB reflects future cash flows, revenues and expenditures, rather than historical values.

2). As the VBB reflects the future, the relevant future periods for the measurement of the VBB have been defined. 
3). Calculation of the assets and the liabilities as discounted cash flows requires an estimation of the level of risk involved in the cash flows and therefore to choose appropriate discount factors. (Note 3) In this we follow the traditional assumptions that limit the joint probability distribution of the future cash flows of a given investment project.

4). The future expenditures are presented as liabilities in the VBB. The liabilities are divided into two classes: (a) derived liabilities and (b) discretionary liabilities. Liabilities to owners of specific factors of production that are a part of the production process of the firm are derived or internal liabilities. (Note 4) Liabilities to providers of general capital like bank loans, bonds and shares are regarded as discretionary or external liabilities.

5). Fama and Miller (1972) describe the relations between assets and liabilities in a balance sheet. They say that the assets (the real side) determine the value of the firm and the liabilities (the financial side) tell us how this value is distributed among different security holders. In an incomplete market, the directional relationship between assets and liabilities gives rise to an optimal capital structure given the risk level of the assets. The VBB allows us to measure it.

\section{VBB and the Financial Economics Valuation Model: From Modigliani-Miller to Agency and Imperfect Competition}

The VBB is consistent with the financial economics valuation model. The classic textbook financial economics valuation model is built on the assumption of complete and perfect markets where all assets and liabilities are continuously traded in public markets. The basic valuation model is derived from the state-preference approach (Arrow, (1964), Debreu, (1959), Hirshleifer, (1965)). As Goldstein et al. (2001) show, the sum of the present value of the claim to funds during solvency and the present value of the claims to funds in bankruptcy is equal to the present value of the claim to EBIT of the value. Hence, in the common valuation model the value is neither created nor destroyed by changes in the capital structure.

Assume that the basic conditions of the state-preference approach hold (Note 5) and that there is a pricing functional P, $P \in M$ such that:

$$
p(1), p(2), \ldots p(S) \quad \forall p(s) \text {. }
$$

Where $p(s)$ is the price at period 1 of $\$ 1$ at period 2 iff state $s$ occurs.

An asset $\mathrm{x}$ of the firm $(1,2, \mathrm{x}, \mathrm{X})$ can be described as:

$$
V a(x)(1)=\sum_{s=1}^{S} P(s) \cdot V a(x)(2, s) \text { at period } 1
$$

Following the state-preference approach, there are a finite number of states of the world that together describe fully the distribution of the cash flows that comprises the asset. The value of the sum of the assets in the VBB of the firm (the value of the firm) is:

$$
V_{A}(1)=\sum_{x=1}^{X} \sum_{s=1}^{S} P(s) \cdot V a(2, s)
$$

The firm issues liabilities against its assets. The value of any given liability $y(\mathrm{y}=1,2, \ldots \mathrm{y}, \mathrm{Y})$ is:

$$
V_{l} y(1)=\sum_{s=1}^{s} P(s) \cdot V_{l} y(2, s)
$$

The value of the liabilities of the firm given the information contained in the VBB is:

$$
V_{l}(1)=\sum_{x=1}^{X} \sum_{s=1}^{S} P_{s} V_{l} \cdot(2, s)
$$

The identity between the assets and the liabilities in the VBB means that, in period 1,

$$
V_{A}(1)=V_{L}(1)
$$

In a world of complete and perfect markets, there are markets for all types of liabilities, including derived securities like wage contracts and other internal securities issued by the firm. (Note 6) In such a world, the separation principle holds, and the results of the famous Modigliani-Miller (1958) study hold, and the value of the firm is independent of its financing decisions as they are interpreted in a broad sense in the VBB. Fama and Miller concluded their discussion of the independence of the financing from the investment decisions as follows: 
"Thus the period 1 market value of the firm is the same under all three different assumptions about financing decisions and in fact is always equal to the period 1 values of the total resources generated by the firm in each possible future state" (The Theory of Finance (1972), pp. 159-160).

The total resources generated by the firm in each possible state of nature are exactly the sum of the assets in the VBB. Extending the basic two-period model of Modigliani and Miller to a multi-period framework like the VBB is straightforward. The contingent value of the debt and equity at time $\mathrm{T}$ can be represented as:

$$
\begin{aligned}
& V_{D}=\left\{\begin{array}{l}
W(T)_{-} i f_{-} W(T)<F \\
F_{-} i f \_F \leq(W(T)
\end{array}\right\} \\
& V_{S}=\left\{\begin{array}{l}
0_{-} \text {if } f_{-} W(T)<F \\
W(T)-F_{-} \text {if _ } F \leq W(T)
\end{array}\right\}
\end{aligned}
$$

Where $V_{D}$ is the value of the debt at time $t$, and $V_{S}$ is the value of stock at time $t$. The value of the firm $W$ at time $t$ is $W(t)=V_{D}(t)+V_{S}(t)$. Let $\mathrm{F}$ be the repayment of the debt upon maturity. If $\mathrm{W}(\mathrm{T})$ exceeds $\mathrm{F}$, the firm can redeem its debt as promised. If $\mathrm{W}(\mathrm{T})$ is less than $\mathrm{F}$, the firm is in default, and all the value of the firm goes to the bondholders. This is true if the firm issues shares and bonds only. In a more general case, the firm issues $\mathrm{N}$ claims to shareholders, bondholders, managers, workers, suppliers, and providers of services. Let the claims be $V_{1}, V_{2}$ $\mathrm{V}_{\mathrm{n}} \ldots \mathrm{V}_{\mathrm{N}}$.

Some of the claims are inclusively defined by the functional $w$ and $t$, such as simple debt to be matured at a certain time $T$. Some claims, such as future salaries and taxes, are not defined directly by $t$.

The primary problem is identifying the forms of the contingent value function, or identifying how these claims are valued. In the two-claim world $\left(\mathrm{V}_{\mathrm{S}}\right.$ and $\left.\mathrm{V}_{\mathrm{D}}\right)$, the illustration is simple:

There exists a pair of contingent value functions $f_{1} f_{2}$ and their arguments $\mathrm{t}$ (time) and $\mathrm{W}$ (the value of the firm). The i-th security (or claim) at time $t \leq T$ can be stated as

$$
V_{i}(t)=f_{i}(W(t), t) \quad \forall \quad i=D, V
$$

For the simple MM case in which we have only common stock and pure debt, for time $\mathrm{t}=\mathrm{T}$ we can draw:

$$
\begin{aligned}
& f_{D}(W, T)=\min [W, F] \\
& f_{S}(W, T)=\max [0, W-F]
\end{aligned}
$$

Once other claims are introduced, particularly claims that are not independent of the EBIT produced by the assets of the firms, the valuation is not as simple as in the MM case. This is because F is dependent on the structure of the claims held by some claimants. Two major groups of claimants that belong to this group are providers of human capital, managers and workers, and providers of inputs to the firm where the inputs are traded in a market of monopolistic competition. In these two cases, we cannot use the general equilibrium approach that was developed by several authors following the MM approach, see for example Garbade (2001); rather, we have to look for different approaches. The extensive literature on agency cost, financial distress, and the economic literature that use game theory approach are the natural place to look for models that are based on imperfect and incomplete markets. A good summary of the different approaches and the implications of the imperfection are found in Brennan and Trigeorgis (2000). Brennan and Trigeorgis distinguish between three stages in the development of valuation models by the degree of control that various stakeholders in the firm have upon the cash flows of a given project over its lifetime. The first-stage models are consistent with the Modigliani- Miller (1958) model of the value of the firm. Capital structure does not matter, because no stakeholder exercises any control on the future cash flows of any given project. (Note 7)

The second-stage models, often referred to as agency cost models, focus on the top management of the firm as a specific group of stakeholders, "agents" of the shareholders, who can affect the future cash flows by their activities. They are motivated by their contracts with the shareholders. Here one can assume that the markets are incomplete, especially where management contracts are concerned. In cases in which liabilities to top management and other 
professionals are an important part of the liabilities issued by the firm, the design of the liabilities to the providers of human capital (presented later in this paper as Financial Congruence) have an effect on the value of the firm. Seed and early stage hi-tech firms are a special case of such a class.

The third-stage models assume that a number of external stakeholders have the ability to affect the future cash flows of investment projects taken by the firm. These may be suppliers, external service providers, and even competitors who may have an indirect effect on the EBIT of the firm through price competition and similar factors. Similar situations are discussed in the industrial organization and new trade theories. Hotelling (1929) initiated the use of spatial analogies in assessing market differentiation. Cromley and Hanink $(1993,2008)$ follow this line to analyze differentiated international markets. The continuum of demand points is partitioned into homogeneous segments by the use of a classification algorithm that minimizes within-group variation. The criteria used for classifying are two indicators of market overlap that have been suggested as important by the new trade theory, proximity of gross national product (GNP), and proximity of per capita GNP. Such models lead to a world of multiple equilibria. (Note 8) The design of the liabilities issued by the firm becomes a part of a strategy based on stochastic dominance and backward induction approach with its advantages and disadvantages as a framework for an economic analysis and managerial application.

The VBB is a valuation instrument that allows for strategic design of liabilitiea and measures their effect on the value of a single firm, or a group of similar firms. The VBB requires some knowledge on the way by which stakeholders of the firm have the ability to influence the future cash flows of the firms and their risk, (such iformation is often in the contracts between start-up entrepreneurs and venture capital (VC) funds), but given the information the value of the capital structure to the firm can be measured.

\section{Risk Class and Financial Congruence}

Once accounting moves from using only past data to allow estimates and forecasts of the management of the firm and/or external professionals, regarding the future we have to measure and to account for the risk profile of the assets and the liabilities as the risk in the future determines the actual outcomes. To do that we define a measure called "financial congruence". Financial congruence measures the relative change in the sum total of the liabilities and the distribution of the change where the total sums of the assets changes. Financial congruence is an ex ante concept. Ex post the value of the assets is always identically equal to the value of the liabilities (including equity). The concept of financial congruence is related to the notion of a risk class. (The concept of a risk class was developed by Fama and Miller, (1972). Consider the following example:

Two firms $i$ and $j$ are in the same risk class iff for all $t, t \in T$

$$
A_{i}(t)=P_{i} A_{j}(t)
$$

and

$$
\begin{gathered}
L_{i}(t)=P_{i} L_{j}(t) \\
\forall 0 \leq P_{i} \leq 1
\end{gathered}
$$

Let $A_{i}(t)$ be the cash flows of asset $\mathrm{A}$ of firm i at period $\mathrm{t}$ and $L_{i}(t)$ be the cash flows of liability $\mathrm{L}$ of firm $\mathrm{i}$ at period $\mathrm{t}$. Pi is a proportionality factor which is the same for all $\mathrm{t}$. Note that, in periods before $\mathrm{t}$, cash flows are uncertain, but for the firms $i, j$ to be in the same risk class, their cash flows are always proportional by the factor Pi and hence perfectly correlated. In the same manner, we can perfectly correlate the firms' cash earnings (Assets) and cash outlays (Liabilities).

Such that at any given $t, t \in T$

$$
\begin{gathered}
A_{i}(t)=P_{i} L_{i}(t) \\
\forall 0 \leq P_{i} \leq 1
\end{gathered}
$$


A sufficient condition for complete financial congruence is that relation (4.3) is true for every asset $A_{i}$ at any given time t. A necessary condition for a complete financial congruence is that the sum total of the assets is in the same risk class as the sum total of the liabilities in the same risk class. The condition holds where Pi is less than one. In this case, the relationship between assets and liabilities is given by:

Such that: $A \equiv L$

$$
A=\sum_{t=1}^{T} \sum_{n=1}^{N} a_{n}(t)=L=P \sum_{t=1}^{T} \sum_{m=1}^{M-1} l_{m}(t)+(1-P) \cdot L \cdot M
$$

Proposition (4.4) implies the possibility of a value-maximizing diversification within the firm. This is not surprising, as financial congruency is important only where there are no complete and perfect markets. In a world of imperfect competition, it is likely that firms (and managers) will decide to diversify as a way to reduce their risk, as they often do. The LHS of the equation above is the sum of all the assets $(n=1,2,3, \ldots . . \mathrm{N})$, owned by firm i. Assets are represented by cash flows over time. The RHS is composed of two parts:

1). Future cash flows of the expenditures (liabilities) minus one, which is proportional to the cash flows of the assets but in proportion which is less than one.

2). The last liability (M) is the liability to the shareholders who are defined as the residual claimants. Shareholders receive whatever is left after all other claims were paid. $0 \leq P \leq 1$ from proposition 4.4 follows that the firm is always solvent and the financial congruency is complete.

What makes the firm solvent at all states is the constraint on P. This is not always the case. Assume that a firm issues a bond that promises to pay the same amount regardless of the states of nature and that this amount is equal to the expected value of the cash flows at any given period. In a complete and perfect market world, this will not alter the value of the firm. In such a world, there is a market price today to any contingent claim. The market knows how to unpack securities that are comprised of a number of basic claims that pay $\$ 1$ given a certain state of the world in a given period. Although the bond issued by the firm promises to pay the same amount in any state of the world, and thus it appears as a riskless bond, the market will acknowledge the embedded option that prices the market risk. Hence, the market will price it according to the riskiness of the underlying assets. (Note 9) Where markets are incomplete and in particular where the current and future actions of some security holders may affect the value of the liabilities of the firm, the constraint on the value of $\mathrm{P}$ does not hold. The firm may find itself insolvent in a certain period, even if it has a positive net present value over time. In such a situation, the absence of financial congruency has an effect on the value of the firm.

Deviations from the perfect and complete markets are obtained where agency cost is introduced. Maurer and Ott (Note 10) show that, where there are costs of financial distress, equity holders will underinvest in an option to expand the business (Note 11). To make valuation in an imperfect market, like the market in which start-up exist, operational there is a need to specify the probability distribution of the cash flows that generate the assets. This is so because financial congruency requires that the probability distribution of the liabilities will be congruent with the probability distribution of the assets. Agmon and Whilborg (1989) provide a simple but effective way to classify uncertain outcomes that can be applied to the risk associated to the assets in the VBB of a given firm.

In order to do so, the information about the past behavior of the cash flows of a given asset is collected. This usually consists of past sales records. The information is then supplemented by any relevant data about the market, competition, regulations, and such. The data is then classified into three categories: Consensus, No-Information, and Either-Or. The three categories are then summarized as specific distributions. The Consensus category is fitted as a normal distribution, the No-Information category is fitted as a uniform distribution, and the Either-Or category into a binomial distribution. The procedure is summarized in the following table.

\begin{tabular}{ll}
\hline Type of Information & Distribution \\
\hline Consensus & Normal \\
\hline No-Information & Uniform \\
\hline Either-Or & Binomial \\
\hline
\end{tabular}


While issuing liabilities, explicit or implicit, the firm considers the distributional nature of its assets. For instance, the sum total of the assets of firm $i$ is represented by a binomial distribution, then financial congruency means that the maximum value of a riskless bond that firm $\mathrm{i}$ can issue is bounded by a payment that is congruent with the low branch of the binomial tree. Such a situation calls for embedding an option in the liability. (Note 12) This is just one simple example. An actual design of liabilities to accomplish financial congruency and maximizing value requires much data such as the $3^{\text {rd }}$ moment of the distribution (Skewness). Let us consider an asymmetric shift in the terminal payout probability profile. The assumption that costs are distributed normally produced a symmetric distribution of project values. Equity holders would prefer instead that this distribution were skewed to the right, which is to say that upside potential was enhanced without sacrificing the financial stability of the firm. We can observe, then, that positive skewness is valuable. (Note 13)

\section{Estimating the VBB as a Valuation Instrument}

In order to see how the VBB can be used in a real situation, we conduct an empirical test for the VBB as an instrument of valuation. We chose to do that on a database of small innovative firms that were backed by venture capital funds and went through what is known as an "exit" through an IPO. The VBB frame is ideal for valuation of such firms, as their balance sheets are very similar in the composition of the assets and liabilities, and they all went through a similar path of growth from the first round investment to the IPO. The empirical work on fair value implementation is yet scarce. Scheibel (2007) compares between the German GAAP method (that ceased to exist after 2004) and IFRS. The results of the study show that German GAAP is significantly more value relevant statistically than IFRS. Ernstberger (2008), using the same database with a different selection criteria, reports the opposite: "comprehensive income under IFRS provides more incremental value relevant information than comprehensive income under US GAAP." Florou and Pope (2012), using an international database, show that enforcement of IFRS creates a stronger demand for equities.

We focus on a simple question. Can we utilize the VBB as an effective measurement tool. We use a dataset of firms from the software industry. All of the firms are venture-capital-backed start-ups that had an IPO at either at NASDAQ or at the Tel Aviv Stock Exchange (TASE) during the period 2000-2007. We use only software firms because of their relative simple assets and liabilities. We use three years' pre-IPO data provided in the prospectus as a part of the IPO as well as post-IPO public data. In table 1 we provide some detailed statistics about the dataset.

\begin{tabular}{|c|c|c|c|c|c|c|}
\hline $\begin{array}{l}\text { \# of firms in } \\
\text { data set }\end{array}$ & $\begin{array}{l}\text { Average VC } \\
\text { valuation (after } \\
\text { the money) M\$ }\end{array}$ & $\begin{array}{l}\text { min } \mathrm{VC} \\
\text { valuation } \\
\text { (after the } \\
\text { money) }\end{array}$ & $\begin{array}{l}\text { Max VC } \\
\text { valuation } \\
\text { (after the } \\
\text { money) }\end{array}$ & $\begin{array}{l}\text { Average } \\
\text { Post IPO } \\
\text { value }\end{array}$ & $\begin{array}{l}\text { Min(per } \\
\text { firm) Post } \\
\text { IPO value }\end{array}$ & $\begin{array}{l}\text { MAX (per } \\
\text { firm) Post } \\
\text { IPO value }\end{array}$ \\
\hline \multirow[t]{5}{*}{35} & 43.1 & 22.1 & 94.4 & 107.3 & 53 & 273 \\
\hline & $\begin{array}{l}\text { Median VC } \\
\text { valuation (after } \\
\text { the money) M\$ }\end{array}$ & $\begin{array}{l}\text { STD of VC } \\
\text { valuation }\end{array}$ & $\begin{array}{l}\text { Skewness } \\
\text { of VC } \\
\text { valuation }\end{array}$ & $\begin{array}{l}\text { Median } \\
\text { POST IPO } \\
\text { value }\end{array}$ & $\begin{array}{l}\text { STD of } \\
\text { market } \\
\text { value }\end{array}$ & $\begin{array}{l}\text { Skewness } \\
\text { of market } \\
\text { value }\end{array}$ \\
\hline & 34 & 18.7 & 1.2 & 94 & 48.3 & 1.7 \\
\hline & $\begin{array}{l}\text { Total Portfolio } \\
\text { Value M\$ (VC } \\
\text { valuation) }\end{array}$ & & & $\begin{array}{l}\text { Total } \\
\text { Portfolio } \\
\text { Value } \\
\text { M\$ (Market } \\
\text { valuation) } \\
\end{array}$ & & \\
\hline & 1,551 & & & 3,864 & & \\
\hline
\end{tabular}

For each of the firms, in our data set we obtain the last private valuation that was done before the IPO. For each firm in the data set, we compute the VBB value based on
A. Projected (expected) sales for 5 years discounted with normal distribution.
B. Projected (possible) value of patents and other IP, discounted with binomial distribution.
C. Other assets, which are typically insignificant in our case, are discounted with a uniform distribution. 
Chart 1 shows the average breakdown of the valuation.

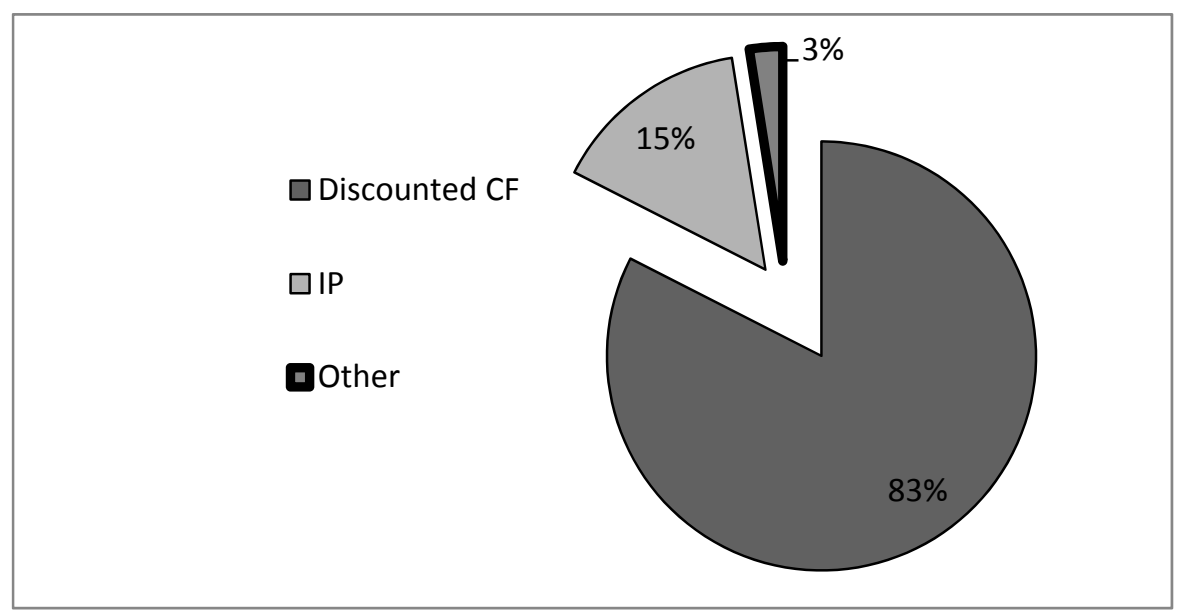

The chart shows the assigned value of the firms to the three categories: future sales, IP, and other. Note that, as these are early stage software firms, they have few if any tangible assets.

We compute the VBB at two points in time:

A. At the last venture capital round. At this point, we match the VBB with the accounting-based value of the balance sheet and the market value, taken from the valuation of the $\mathrm{VC}$ fund.

B. At the IPO. At this point, which is either 1 year or two years after the $1^{\text {st }}$ valuation, we match the VBB against the balance sheet and the market price taken at:

a. The IPO

b. Average 6 months post-IPO price

We run several types of VBB valuations at each point of time; we present a method that is based on a Genetic Algorithm (GA) software package - Evolver. (Note 14) This method allows us to reach a set of plausible solutions to the multi-dimensional problem of many distributions, creating countless discount factors.

In Table 2 we provide the leading (in terms of fitness) solution and the underlying distribution assumptions.

\section{Panel A - Solution Fitting - unbounded}

\begin{tabular}{llll}
\hline Factor & Expected Sales & Intellectual Property & Miscellaneous \\
\hline Underlying distribution & Normal/Log-normal & Binomial & Uniform \\
\hline Factors (Range) & $\mathrm{STD}(0.3-0.6), \mathrm{R}(0.1-0.4)$ & $\mathrm{P}(0.001-0.999)$ & $\begin{array}{l}\mathrm{A}, \mathrm{B}(\mathrm{A}<\mathrm{B}) \\
(0.001-\mathrm{V} / 10)\end{array}$ \\
\hline Solutions (1) & $\mathrm{STD}=0.4123, \mathrm{R}=0.189$ & $\mathrm{P}=0.323$ & $\mathrm{~A}=0.001, \mathrm{~B}=\mathrm{V} / 38.85$ \\
\hline Solutions (2) & $\mathrm{STD}=0.4541, \mathrm{R}=0.212$ & $\mathrm{P}=0.544$ & $\mathrm{~A}=0.001, \mathrm{~B}=\mathrm{v} / 12.34$ \\
\hline Solutions (3) & $\mathrm{STD}=0.532, \mathrm{R}=0.271$ & $\mathrm{P}=0.001$ & $\mathrm{~A}=0.001, \mathrm{~B}=0.002$ \\
\hline
\end{tabular}

Panel B - Solution Fitting - bounded

\begin{tabular}{llll}
\hline Factor & Expected Sales & Intellectual Property & Miscellaneous \\
\hline Underlying distribution & Normal/Log-normal & Binomial & Uniform \\
\hline Factors (Range) & STD $(0.3-0.6), \mathrm{R}(0.1-0.4)$ & $\mathrm{P}(0.001-0.999)$ & $\begin{array}{l}\mathrm{A}, \mathrm{B}(\mathrm{A}<\mathrm{B}) \\
(0.001-\mathrm{V} / 10)\end{array}$ \\
\hline Solutions (1) & $\mathrm{STD}=0.462, \mathrm{R}=0.236$ & $\mathrm{P}=0.001$ & $\mathrm{~A}=0.001, \mathrm{~B}=0.002$ \\
\hline Solutions (2) & $\mathrm{STD}=0.494, \mathrm{R}=0.249$ & $\mathrm{P}=0.001$ & $\mathrm{~A}=0.001, \mathrm{~B}=0.002$ \\
\hline Solutions (3) & $\mathrm{STD}=0.418, \mathrm{R}=0.218$ & $\mathrm{P}=0.001$ & $\mathrm{~A}=0.001, \mathrm{~B}=0.002$ \\
\hline
\end{tabular}


Table 2 Panels A and B show the Evolver's top 3 solutions to the unbounded and then the bounded portfolios. A solution is reached once all the parameters (together) reach a local optimizing point. Given the complexity of the analysis, multi-solution frame can be expected. The bounded portfolio's solutions tend to be corner solutions for the binomial and the uniform distributions.

The goal-seeking function matches the value of the whole portfolio of firms with a single set of plausible discount factors that will yield a VBB value that can be compared to the value of the portfolio as per the investment of the VC funds. This measure was done twice to review the robustness of the mechanism. First, we run the model without barriers on the matching of two valuation of a single firm; e.g., we allow the VBB of a single firm to differ from the $\mathrm{VC}$ valuation as long as the total value of the portfolio matches. Second, we run the same evolving model, when the VBB value of each specific firm is set to match the VC valuation with a suppleness of $\pm 5 \%$.

The results of the two valuations are reported in Table 3.

\begin{tabular}{|c|c|c|c|}
\hline $\begin{array}{l}\text { Firm \# (ranked by VC } \\
\text { valuation (matched to Table } 3 \text { ) }\end{array}$ & $\begin{array}{l}\text { VBB Unbounded } \\
\text { Valuation }(\mathrm{M} \$)\end{array}$ & $\begin{array}{l}\text { VBB Bounded } \\
\text { Valuation }(\mathrm{M} \$)\end{array}$ & VC Valuation (M\$) \\
\hline 1. & 24.20 & 21.00 & 22.1 \\
\hline 2. & 27.40 & 22.82 & 24.6 \\
\hline 3. & 28.07 & 25.09 & 25.2 \\
\hline 4. & 23.92 & 27.56 & 27.7 \\
\hline 5. & 33.19 & 28.38 & 28.5 \\
\hline 6. & 39.80 & 29.59 & 29.1 \\
\hline 7. & 26.42 & 30.80 & 29.5 \\
\hline 8. & 31.18 & 31.05 & 29.8 \\
\hline 9. & 34.17 & 31.39 & 30.1 \\
\hline 10. & 24.86 & 31.40 & 30.2 \\
\hline 11. & 37.70 & 32.06 & 30.3 \\
\hline 12. & 25.98 & 32.68 & 30.6 \\
\hline 13. & 24.83 & 32.86 & 30.8 \\
\hline 14. & 32.02 & 33.12 & 32.8 \\
\hline 15. & 29.97 & 33.38 & 33.0 \\
\hline 16. & 30.94 & 33.38 & 33.5 \\
\hline 17. & 31.03 & 33.46 & 33.7 \\
\hline 18. & 35.74 & 34.04 & 33.9 \\
\hline 19. & 36.35 & 35.35 & 34.1 \\
\hline 20. & 38.83 & 35.99 & 34.1 \\
\hline 21. & 32.53 & 38.66 & 35.9 \\
\hline 22. & 35.34 & 39.34 & 37.3 \\
\hline 23. & 42.71 & 39.46 & 37.7 \\
\hline 24. & 35.01 & 41.27 & 38.2 \\
\hline 25. & 58.70 & 47.31 & 49.8 \\
\hline 26. & 54.19 & 48.02 & 50.1 \\
\hline 27. & 49.76 & 51.35 & 53.8 \\
\hline 28. & 45.60 & 56.17 & 58.0 \\
\hline 29. & 67.66 & 56.82 & 60.0 \\
\hline 30. & 50.44 & 61.48 & 65.3 \\
\hline 31. & 61.79 & 61.96 & 67.5 \\
\hline 32. & 60.43 & 64.32 & 67.7 \\
\hline 33. & 78.51 & 67.67 & 70.5 \\
\hline 34. & 92.20 & 87.40 & 80.9 \\
\hline 35. & 98.61 & 88.11 & 84.0 \\
\hline Total & $1,580$. & 1,553 & 1,551 \\
\hline
\end{tabular}


The table shows the single three valuations for each firm in the database: The venture capital funds after the money valuation, the Bounded VBB, and the Unbounded VBB. Though the unbounded valuations vary significantly from the VCF, they capture the fundamental value. As we can see, when the optimization is unconstrained, the values that the firms receive are inconsistent with their actual valuations. When we limit the degrees of freedom, we receive multiple solutions. The most plausible one when focusing on the DF factor of expected cash flow from future sales involves a corner solution on the intellectual property of the firms. This is a thought-provoking point, as this solution hints that the patents and other property rights of software firms are small. Kief and Paredes (2011) suggest that, in a comprehensive legislative framework, patents and other intellectual property rights in general may well be overpriced in book value compared to their economic value. The overpricing is especially likely in highly competitive segments where the entrance barriers are low. A plausible example is the software industry.

We use Latin Hypercube simulation using the "@Risk" software package to simulate the range of accepted discount factors. (Note 15)

The discount factor we receive is in the range of $22.1-24.5 \%$, only slightly lower the market's "thumb figure" of $25 \%$. In the next stage, we repeat the same calculation at the post-IPO stage. Here we match the VBB figures with the 6-month average firm's trading value. The results are reported in Table 4 below.

\begin{tabular}{|c|c|c|c|}
\hline $\begin{array}{l}\text { Firm \# (ranked by VC } \\
\text { valuation }\end{array}$ & $\begin{array}{l}\text { VBB Unbounded Valuation } \\
\text { (M\$) }\end{array}$ & $\begin{array}{l}\text { VBB Bounded } \\
\text { Valuation }(\mathrm{M} \$)\end{array}$ & $\begin{array}{l}6 \text { month average post-IPO } \\
\text { Valuation }(\mathrm{M} \$)\end{array}$ \\
\hline 1. & 77.17 & 64.1 & 65.6 \\
\hline 2. & 85.51 & 76.8 & 74.9 \\
\hline 3. & 76.43 & 59.1 & 60.0 \\
\hline 4. & 53.2 & 58.9 & 57.4 \\
\hline 5. & 74.22 & 77.0 & 78.5 \\
\hline 6. & 98.24 & 96.3 & 97.8 \\
\hline 7. & 94.67 & 105.3 & 105.6 \\
\hline 8. & 53.2 & 61.9 & 63.8 \\
\hline 9. & 111.96 & 115.1 & 115.4 \\
\hline 10. & 92.33 & 87.8 & 88.8 \\
\hline 11. & 71.2 & 73.6 & 75.4 \\
\hline 12. & 78.6 & 52.5 & 54.1 \\
\hline 13. & 86.92 & 93.0 & 93.0 \\
\hline 14. & 111.13 & 119.1 & 118.3 \\
\hline 15. & 73.26 & 95.7 & 95.2 \\
\hline 16. & 108.8 & 114.0 & 112.7 \\
\hline 17. & 97.21 & 90.4 & 88.5 \\
\hline 18. & 58.54 & 53.8 & 53.5 \\
\hline 19. & 53.2 & 88.9 & 90.6 \\
\hline 20. & 139.57 & 110.3 & 110.5 \\
\hline 21. & 112.3 & 97.0 & 95.2 \\
\hline 22. & 77.21 & 104.6 & 103.8 \\
\hline 23. & 148.02 & 82.4 & 84.0 \\
\hline 24. & 84.03 & 109.4 & 107.7 \\
\hline 25. & 124.4 & 92.2 & 90.8 \\
\hline 26. & 106.55 & 67.3 & 66.9 \\
\hline 27. & 153.11 & 175.7 & 174.2 \\
\hline 28. & 122.79 & 88.7 & 87.5 \\
\hline 29. & 57.22 & 166.4 & 165.7 \\
\hline 30. & 122.7 & 158.7 & 156.8 \\
\hline 31. & 199.8 & 128.4 & 126.7 \\
\hline 32. & 262.11 & 212.7 & 211.3 \\
\hline 33. & 238.6 & 207.1 & 205.6 \\
\hline 34. & 239.72 & 82.2 & 81.6 \\
\hline 35. & 178.8 & 272.1 & 273.6 \\
\hline Total & 4,068 & 3,851 & 3,864 \\
\hline
\end{tabular}


The table shows the single three valuations for each firm in the database: The market's value, the Bounded VBB, and the Unbounded VBB. Though the unbounded valuations vary significantly from the market's value, they capture in most cases the value and the increase in value since the prior valuation. Again, the unconditioned measure yielded discount factors that were too dispersed to have statistical meaning. When we apply the conditioned measures, we receive discount factors in the range of 20.4-23.1\%. Note that, because of the size of the database, we did not split the database over time. Another noteworthy result is the ability of the VBB to capture correctly the increase in valuation.

In Chart 2 we plot the bounded and unbounded VBB models against the actual return on the firms. The bounded model provides, as expected, a "thin" cloud. Yet more important is that the unbounded model holds a significant correlation with actual return.

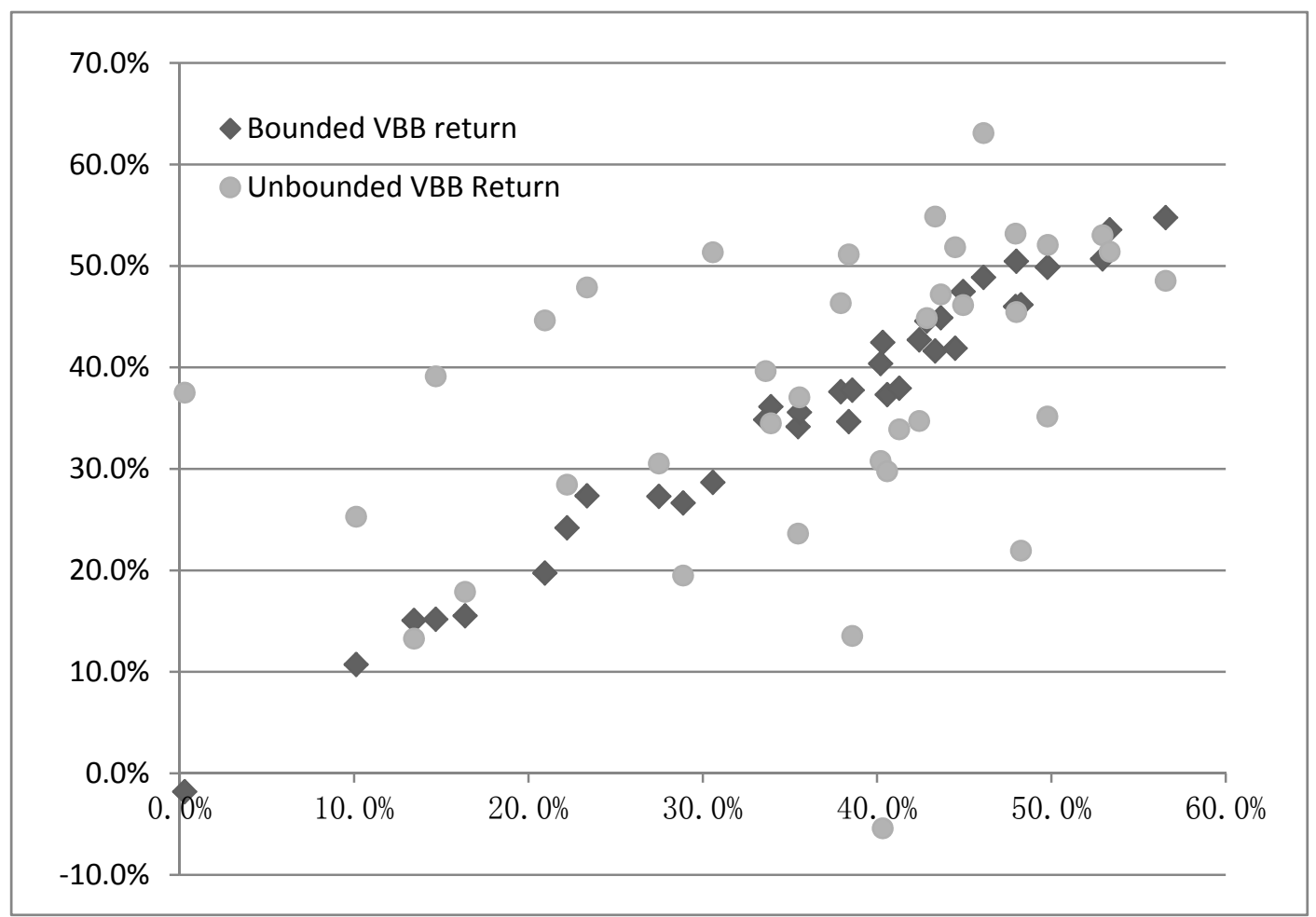

Table 5 and the following charts shows the unconditional VBB valuations deltas, computed as the "return over the holding period" compared to the deltas in market price computed as the "6-month Avg. price over "VC VALUATION."

\begin{tabular}{lll}
\hline $\begin{array}{l}\text { Firm \# (ranked by VC valuation } \\
\text { (matched to Table 3) }\end{array}$ & $\begin{array}{l}\text { Unbounded VBB Return } \\
\text { (Annual) }\end{array}$ & Actual return (Annual) \\
\hline 1. & $47.2 \%$ & $43.7 \%$ \\
\hline 2. & $46.1 \%$ & $44.9 \%$ \\
\hline 3. & $39.6 \%$ & $33.6 \%$ \\
\hline 4. & $30.5 \%$ & $27.5 \%$ \\
\hline 5. & $30.8 \%$ & $40.2 \%$ \\
\hline 6. & $35.1 \%$ & $49.8 \%$ \\
\hline 7. & $53.0 \%$ & $52.9 \%$ \\
\hline 8. & $19.5 \%$ & $28.9 \%$ \\
\hline 9. & $48.5 \%$ & $56.6 \%$ \\
\hline 10. & $54.9 \%$ & $43.3 \%$ \\
\hline 11. & $23.6 \%$ & $35.5 \%$ \\
\hline 12. & $44.6 \%$ & $20.9 \%$ \\
\hline 13. & $51.8 \%$ & $44.5 \%$ \\
\hline
\end{tabular}




\begin{tabular}{lll}
\hline 14. & $51.4 \%$ & $53.3 \%$ \\
\hline 15. & $34.7 \%$ & $42.4 \%$ \\
\hline 16. & $52.1 \%$ & $49.8 \%$ \\
\hline 17. & $46.3 \%$ & $37.9 \%$ \\
\hline 18. & $17.9 \%$ & $16.4 \%$ \\
\hline 19. & $13.5 \%$ & $38.6 \%$ \\
\hline 20. & $53.2 \%$ & $47.9 \%$ \\
\hline 21. & $51.1 \%$ & $38.4 \%$ \\
\hline 22. & $29.8 \%$ & $40.6 \%$ \\
\hline 23. & $51.3 \%$ & $30.6 \%$ \\
\hline 24. & $33.9 \%$ & $41.3 \%$ \\
\hline 25. & $28.4 \%$ & $22.2 \%$ \\
\hline 26. & $25.3 \%$ & $10.1 \%$ \\
\hline 27. & $45.4 \%$ & $48.0 \%$ \\
\hline 29. & $39.1 \%$ & $14.7 \%$ \\
\hline 30. & $-5.4 \%$ & $40.3 \%$ \\
\hline 31. & $34.5 \%$ & $33.9 \%$ \\
\hline 32. & $47.9 \%$ & $23.4 \%$ \\
\hline 33. & $63.1 \%$ & $46.1 \%$ \\
\hline 34. & $44.8 \%$ & $42.9 \%$ \\
\hline 35. & $37.5 \%$ & $0.3 \%$ \\
\hline & $21.9 \%$ & $48.3 \%$ \\
\hline
\end{tabular}

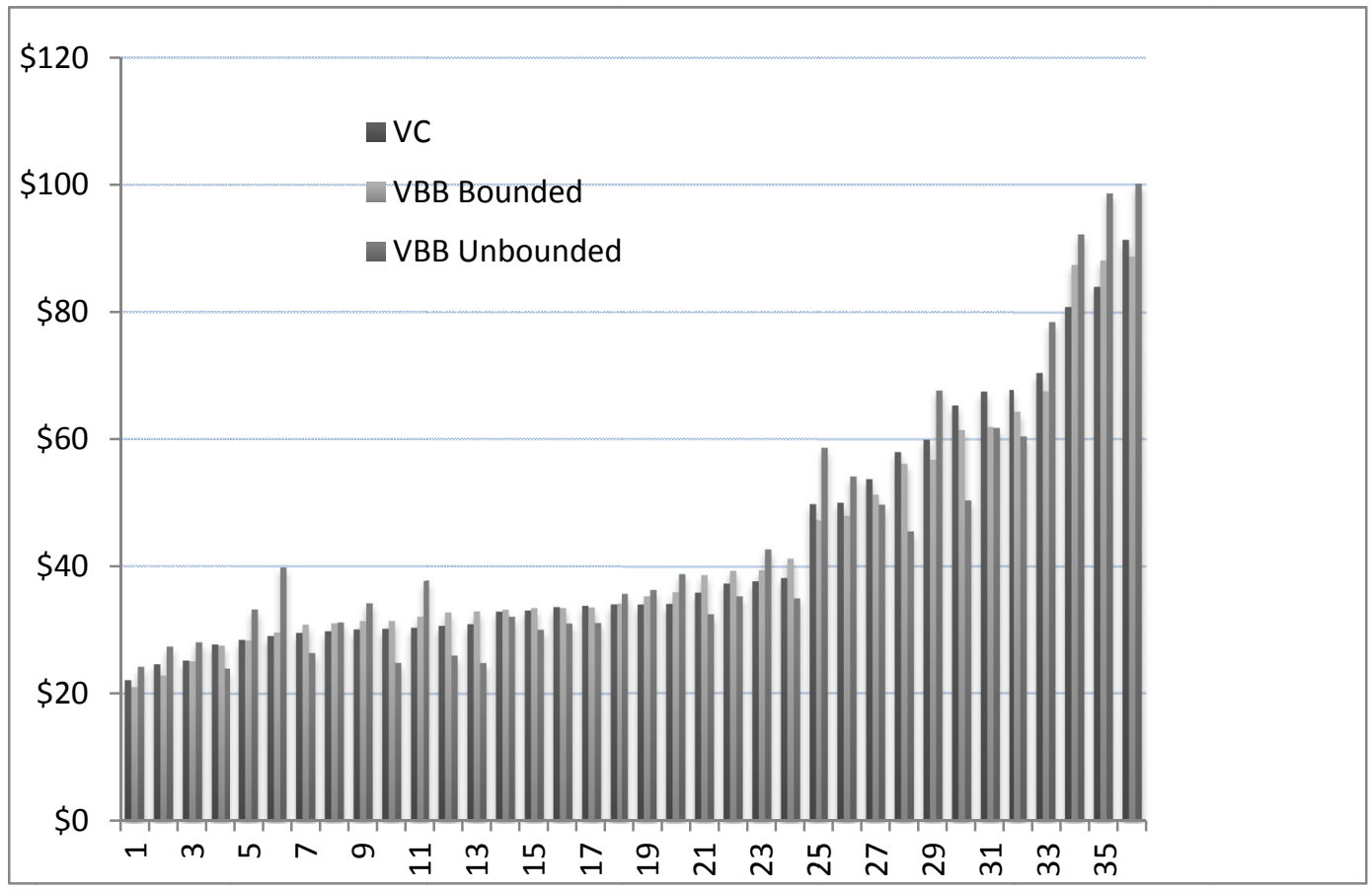

Chart 3A graphs the single three valuations for each firm in the database: The Venture capital funds after the money valuation, the Bounded VBB, and the Unbounded VBB. Though the unbounded valuations vary significantly from the $\mathrm{VCF}$, they capture the fundamental value.

The results support our main theoretic hypothesis: VBB is an effective tool to value young firms with minimal tangible assets and which provide limited financial information by using simple statistical measures and, by doing so, bridging between finance and accounting. 
Table 6 summaries the findings. A significant increase in the average and median values is accompanied by a similar increase in the volatility. The focal observation is the significant correlation between the VBB new valuations and the actual increases in value.

\begin{tabular}{lllllll}
\hline & VBB & VBB & & VBB & VBB & \\
& Unbounded & Bounded & VC & Unbounded & Bounded & MARKET \\
\hline Average Value & 43.89 & 43.15 & 43.10 & 113.01 & 107.59 & 107.34 \\
\hline Median Value & 35.54 & 34.70 & 34.00 & 97.73 & 94.48 & 94.08 \\
\hline STD & 21.00 & 18.27 & 18.73 & 53.76 & 48.40 & 48.35 \\
\hline Skew & 1.50 & 1.31 & 1.16 & 1.36 & 1.67 & 1.71 \\
\hline Correlation & 0.920 & 0.990 & & 0.62 & 0.98 & \\
\hline
\end{tabular}

\section{Conclusions}

The advent of the knowledge economy introduces the need to use future estimates as data for valuation. We present, discuss, and test an instrument called the value-based balance sheet (VBB), which provides a measurement of the value of the firm that takes into account forecasts about the future in a consistent way with both financial economics and the IFRS fair value measurement. The VBB highlights the need for risk congruence when markets are incomplete. This is of particular relevance in a world where labor contracts become more flexible and involves risk taking by labor. We show that the VBB can be estimated given available data. As time goes by and managers, analysts, and auditors use future estimates of revenues and expenditures in a commonly agreed way, the VBB and VBB-like measurement instruments will become common in financial analysis.

\section{References}

Agmon, T., \& Whilborg, C. (1989). A Probabilistic of International Trade Risk: Quantification of International Trade Outcomes. In Agmon and Hekman (Eds.), Trade Policy and Corporate Business Decisions. Oxford University Press, New York.

Arrow, K. J. (1964). The Role of Securities in the Optimal Allocation of Risk Bearing. Review of Economic Studies, 31, 91-96.

Brennan, M. J., \& Trigeorgis, L. (eds.) (2000). Project Flexibility, Agency, and Competition, New Developments in the Theory and Applications of Real Options. Oxford University Press, New York.

Debreu, G. (1959). The Theory of Value. John Wiley \& Sons, Inc., New York.

Dialynas, C., Durn, S., \& Ritchie, J. (2001). Convertible securities and Investment characteristics. In Fabozzi, F. (Ed.), Fixed Income Securities. McGraw-Hill.

Ernstberger, A. (2008). The value relevance of comprehensive income under IFRS and US GAAP: empirical evidence from Germany. International Journal of Accounting, Auditing and Performance Evaluation, 5(1).

Fama, E. F., \& Miller, M. H. (1972). The Theory of Finance. Holt, Rinehart and Wilson, New York.

Florou, A., \& Pope, P. F. (2012, November). Mandatory IFRS Adoption and Institutional Investment Decisions. The Accounting Review, 87(6).

Garbade, E. (2001). Pricing Corporate Securities as Contingent claims. MIT Press.

Goldstein, R., Nengjiu, J., \& Hayne, L. (2001). An EBIT - Based Model of Dynamic Capital Structure. The Journal of Business, 74, 483-512.

Hanink, D. M., \& Cromley, R. G. (1993, March). Univariate Classification of differentiated international Markets. Environment-and-Planning, 25(3), 409-24.

Hanink, D. M., \& Cromley, R. G. (2008, October). Locational Equilibria in Weberian Agglomeration. Geographical Analysis, 40(4), 401-421.

Hirshleifer, J. (1965). Investment Decision under Uncertainty: Choice Theoretic Approaches. Quarterly Journal of Economics, 79, 509-536.

Hotelling, H. (2011, May). Stability in Competition. Economic Journal, 39, 41-57.

IFRS 13. (2011, May). Fair Value Measurements, Project Summary and Feedback Statement. 
Kief, S., \& Paredes, T. A. (2011). Perspectives on Commercializing Innovation. Cambridge University Press.

Maurer, D. C., \& Ott, S. H. (2000). Agency Costs, Underinvestment and Optimal Capital Structure. In Brennan and Trigeorgis, (Eds.), Project Flexibility, Agency and Competition. Oxford University Press, New York.

Modigliani, F., \& Miller, M. H. (1958). The Cost of Capital, Corporation Finance, and the Theory of Investment. American Economic Review, 48, 261-297.

Modigliani, F., \& Miller, M. H. (1963). Corporation Income Taxes and the Cost of Capital: a Correction. American Economic Review, 53, 433-443.

Myers, S. (1977). The Determinations of Corporate Borrowing. Journal of Financial Economics.

Owen, R. F., \& Ulph, D. (2002, August). Sunk Costs, Market Access, Economic Integration and Welfare. Review of International Economics, 10(3), 539-55.

Rode, D., Lewis, P., \& Dean, S. (2003). Probabilistic risk analysis and project capital structures. Journal of Structured and Project Finance, New York: Summer, 9(2), 65.

Schiebel, A. (2007). Value Relevance of German Gaap and IFRS Consolidated Financial Reporting: An Empirical Analysis on the Frankfurt Stock Exchange. Available at SSRN.

Trigeorgis, L. (1996). Real Options. The MIT Press.

\section{Notes}

Note 1. It is so only for simplicity. The VBB restricts the total variation to be the same for the assets side and the liabilities side. Each and any asset/liability can have a different distribution with different moments.

Note 2. The markets in this case represent the loaners. They estimate the risks concerning the cash flows of the sales, assets, expenditures, and derived liabilities.

Note 3. It is likely that any source of revenues (for example, the sales of a given product in a given market) and any expenditure (for example, a certain input like energy) have their own riskiness. Yet for measurement, it is useful to find a small number of typical distributions that can describe the different classes of the riskiness of the future cash flows that comprise the assets and the liabilities. Such an approach is presented in Section 4 below.

Note 4. These liabilities can be to employees (future wages and other compensation packages), suppliers, service providers, the government, etc. These liabilities are often ignored, or they appear only in a partial way in a standard accounting balance sheet. The internal liabilities are derived directly from the arrangements that the firm has with its suppliers, including the suppliers of labor and human capital. Once the firm arranges these, there are other financial needs that are met by issuing external liabilities. Structuring these liabilities in terms of whether to issue debt or equity, borrow money from the bank, or issue any derivatives is a managerial decision given the total needs of the firm. This decision is not independent from the nature of the assets and the nature of the derived (internal) liabilities.

Note 5. At period 1, suppose that investors agree that there are a finite number $\mathrm{S}$ of mutually exclusive possible states of the world at period 2 and that, for a given set of decisions made by the firms (at period 1), the market value of firm $\mathrm{i}$ if a certain state "s" occurs is $\mathrm{V}_{\mathrm{i}}(\mathrm{t}=2, \mathrm{~s})$.

Note 6. A perfect market world means that an employee who has an implicit promise of the firm to pay him a certain sum, contingent on the success of the business plan of the firm, can sell such an implicit liability in the market today.

Note 7. This is a direct outcome of how the perfect and complete projects undertaken by the firm determine its value. The capital structure is just a way to allocate the value generated by the firm among the suppliers of capital. All other factors of production are paid at the going market rate, and the firm faces an infinitely elastic supply curve of such factors.

Note 8. The analysis of various possible values of the market values as multiple equilibria is based on Lintner's

equilibrium of the firm market value $V_{i 0}=\frac{\bar{V}_{i 1}-\gamma \sum_{j=1}^{n} \bar{\sigma}_{i j}}{1+r_{f}}$, whereas the end-of-period value of firm $i$ is denoted by $\widetilde{V}_{i 1}$,

and it is normally distributed with mean $\bar{V}_{\mathrm{i} 1}$ and standard deviation $\bar{\sigma}_{\mathrm{i}}$. The market value $\mathrm{V}_{\mathrm{i} 0}$ simultaneously 
determines the rates of return, the standard deviation and the covariance of returns, the proportion of each firm in the market portfolio, and the beta as the outcome of this equilibrium.

Note 9. In a complete market with full information, it is assumed that this adjustment is costless.

Note 10. See Brennan and Trigeorgis, "Project Flexibility, Agency, and Competition."

Note 11. Underinvestment is measured relative to ARGMAX (investment) that maximizes the value of the firm. If as shown, underinvestment is a result of the agency cost of the debt, the agency cost of the debt is the result of the decision of management to maximize the value of the shareholders rather than the value of the company.

Note 12. In firms where employees' compensation comprises the lion's share of the liabilities and the assets cash flows are represented by binomial distributions, it is likely that financial congruency means combining fixed wages (liabilities) with bonuses (options).

Note 13. Rode et at. (2003) show that projects that promote upside potential benefit the equity holders directly, even if variance is unchanged. More significantly for our purposes however, is the observation that skewness is often invisible to conventional best case/base case/worst case assessments of projects, because such analysis gives insufficient attention to probabilities, and the representation of projects via only discrete stylized outcomes admits a virtual continuum of possible outcomes, all of which could share the same points yet remain vastly different.

Note 14. In a genetic algorithm, a population of strings which encode candidate solutions (called individuals, creatures, or phenotypes) to an optimization problem evolves toward better solutions. The evolution usually starts from a population of randomly generated possible solutions and happens in generations. In each generation, the fitness of every individual solution in the population is evaluated, and multiple individuals are stochastically selected from the current population (based on their fitness) and modified (recombined and possibly randomly "mutated," as we use the genetic phrase) to form a new population. The new population is then used in the next iteration of the algorithm. Commonly, the algorithm terminates when either a maximum number of generations has been produced or a satisfactory fitness level has been reached for the population. If the algorithm has terminated due to a maximum number of generations, a satisfactory solution may or may not have been reached.

Note 15. Latin hypercube sampling (LHS) is a statistical method for generating a distribution of plausible collections of parameter values from a multidimensional distribution. In the context of statistical sampling, a square grid containing sample positions is a Latin square IFF there is only one sample in each row and each column. A Latin hypercube is the generalization of this concept to an arbitrary number of dimensions, whereby each sample is the only one in each axis-aligned hyperplane containing it. The maximum number of combinations for a Latin Hypercube of divisions and variables (i.e., dimensions) can be computed with the following formula: $\left(\prod_{n=0}^{M-1}(M-n)\right)^{N-1}=(M !)^{N-1}$

For example, a Latin hypercube of divisions with variables (i.e., a square) will have 24 possible combinations. A Latin hypercube of divisions with variables (i.e., a cube) will have 576 possible combinations. The difference between Latin Hypercube sampling and random sampling ("Monte Carlo") can be explained as follows:

1. In random sampling new sample points are generated without taking into account the previously generated sample points. One does thus not necessarily need to know beforehand how many sample points are needed, while In LHS one must first decide how many sample points to use and for each sample point remember in which row and column the sample point was taken.

2. In LHS, the sample space is divided into equally probable subspaces. All sample points are then chosen simultaneously making sure that the total ensemble of sample points is a LH sample and that each subspace is sampled with the same density.

Thus, LHS ensures that the ensemble of random numbers is a very good representative of the real variability and that the ensemble of random numbers is representative of the real variability whereas traditional random sampling is just an ensemble of random numbers without any guarantees. 